\title{
Manifestation of elements of sustainable development: readiness for environmentally oriented activities of learners of the construction university
}

\author{
Mikhail Leontev ${ }^{1, *}$ \\ ${ }^{1}$ Moscow State University of Civil Engineering, Yaroslavskoe shosse, 26, 129337, Moscow, Russia
}

\begin{abstract}
This study allowed to assess the level of ecological consciousness and environmentally oriented behavior of learners of the construction university. Advance of the principles of the concept of sustainable development, its implementation means association the components: social, economical and ecological (environmental protection). The formation of a new ecological consciousness and behavior is required, and education plays a significant role in this. Architects and builders can have a significant impact on restoring ecological balance and ensuring a high quality of life for the population. The study revealed learners' awareness of the problems of construction and designing green buildings, expressed confidence in the further development of this area, and revealed the expression of aspects of environmentally oriented behavior. No one claimed to have a deep understanding of sustainable development, although many respondents were familiar with this concept. The desire of the respondents to demonstrate environmentally oriented behavior in practice was not significantly manifested. Architects and builders need to be encouraged to promote environmentally responsible professional solutions to protect the health and well-being of the population and the healthy ecosystem.
\end{abstract}

\section{Introduction}

In recent decades, the world community has formulated a new idea for arrangement a future society, the meaning of which is to solve the global problems of mankind, develop civilization and improve the quality of life, preserve natural resources for the current and next generation. This approach is called the concept of sustainable development [1].

Large-scale economic activity caused global problems, most of which arose as a result of the separation of a man from the natural environment (the dominance of the social principle in a man over the natural one). This process was most clearly manifested in the $\mathrm{XX}$-XXI centuries, in the conditions of industrialization, urbanization, computerization, globalization. Humanity has realized that if social development continues to follow the same way of expanding destructive economic activity, global problems will only increase

*Corresponding author: miillen@ rambler.ru 
over time, and can lead to a global environmental disaster. Ecosystems of the biosphere of Earth can no longer satisfy growing human needs. The society realized that the models of the economy and social structure of the twentieth century adversely affect the environment, so humanity needs a new and safer way of development.

On October 20, 1987, at a plenary meeting of the UN General Assembly, a resolution was adopted defining the basic principle of sustainable development of the Bruntland Commission: sustainable development meets the needs of the present, but does not compromise the ability of future generations to meet their needs [2].

The Talloire Declaration, created by university rectors in 1990, expresses deep concern about the increasing magnitude and speed of pollution and environmental degradation, the current depletion of natural resources. The tasks of stabilizing the population, introduction of environmentally friendly technologies and restoration of environmental components as key points of a fair and stable future for all humanity living in harmony with nature are formulated [3].

During the existence of the concept of sustainable development, it was repeatedly revised and supplemented. A new stage in the development of the concept was the adoption in 2015 of seventeen new The Global Sustainable Development Goals, which, according to the 2030 Agenda, are planned to be achieved within the next fifteen years. The United Nations (UN) in its educational companies focuses on the fact that the time has come for global action and every resident of the Earth can and should contribute to the achievement of the Goals, because the fate of all mankind depends on it [4].

Currently, there is a growing understanding that the common tasks of overcoming the global crisis can be solved only by joint efforts of the states of the world. At the same time, every resident of the Earth must change the goals and the nature of his (her) life, to form in his (her) mind a new worldview that meets the principles of the Concept of sustainable development. This Concept was created as a result of combining three main components: economic, social and environmental (environmental protection) [5].

The social component of the Concept is described as an indicator of the quality of life of the population. At the same time, it is necessary to take into account: social justice, fair distribution of benefits, elimination of poverty, free and high-quality education and health care, high life expectancy, high-quality health, opening opportunities for the realization of individual's abilities, interests, inclinations, respect for human rights, free access to culture, ensuring security, democratic self-government (democracy). The social component is directly related to education [6].

According to J. Crotty and S.M. Hall, effective education can be considered as the core of the implementation of sustainable development strategies in Russia. Only an educated society, with great scientific potential and high qualifications, is able at the technical level to ensure the development and dissemination of environmentally friendly technologies (in the construction industry these are: 3D construction, green construction, smart homes, nonwaste industries), create a Code for sustainable development etc. [7]

In many of the world's leading universities, elements of sustainable development are being introduced. A number of innovations in Russian higher education fully comply with the principles of sustainable development, although they sometimes relate to the educational process only indirectly. At the same time, innovations can be both systemic in nature and can be applied as separate resource-saving technologies.

A vivid example of the development of the environmental management system in higher education can be seen in the UK, where there are many programs and projects to promote the implementation of the system, and to evaluate the environmental performance of universities.

A variety of programs also exist in a number of countries: USA, Canada, Germany, France and others. There are international organizations that bring together leading 
universities for sustainable development.An example is the Association for the Advancement of Sustainability in Higher Education (AASHE), the International Alliance of Research Universities (IARU). AASHE is an association of the colleges and universities that work to create a sustainable future.

AASHE sees a successful, equitable and ecologically healthy world in the future in which higher education plays a vital role in ensuring people's understand of the interdependence between social, demographic and economical problems, as well as their ability to meet the challenges of sustainability [8].

The Russian Federation has developed a National Education Strategy for Sustainable Development, as well as an Action Plan for the formation and development of education for sustainable development.

Following the greening of all spheres of society, environmental components and problems of sustainable development penetrate the content of academic disciplines at a technical university. For example, "Fundamentals of Ecology", "Metrology, Standardization, Certification and Quality Management" (bachelor's degree), "Energy Saving and Energy Efficiency" (master's degree).

The concept of sustainable development calls for paying special attention to the environmental component in all its diversity. This also implies the preservation of natural ecosystems, the rational use of natural resources, the reduction of negative environmental impacts, the spread of environmental knowledge and the improvement of ecological culture. And also this concept calls for the principle of environmental responsibility to be universally applied in making managerial decisions.

Currently, the development strategies of higher education institutions in Russia are dominated by social-and-economic development, and the environmental component is fading into the background. The environmental aspect as a whole plays a minor role in the development strategy of educational institutions of higher education, for which there are a number of reasons.

First of all, it should be noted that the environmental aspect does not directly express itself in the directions of the university, but rather indirectly manifests itself in each of them. This approach causes a number of difficulties in the transition to sustainable development and functioning based on its principles of the educational institution. For example, the justification of the need to introduce one or another environmental initiative requires its "adjustment" to other areas of the university, and is not taken for granted, as in foreign universities.

Difficulties are caused by the fact that, as a rule, the leadership of Russian universities is only indirectly familiar with the concept of sustainable development. Therefore, when making strategic decisions, representatives of the administration are more guided by the principles of social-and-economic development. The transition to sustainable development is easiest to implement through the implementation and maintenance of environmental initiatives. The authority and responsibility for the environmental aspects of each of the subsystems: managerial, material, technical, scientific, educational social, are in the competence of various administrative systems of the university. Therefore, there is no integrated management of environmental aspects, they are not connected to the system, which makes it difficult to introduce new environmental initiatives. For these reasons, the activities carried out in Russian universities in the field of ecology, and therefore in the field of education for sustainable development, are rather fragmented, while consistency and an integrated approach are the basis for sustainable development.

While effective management has an important role to play in the implementation of the principles of sustainable development. The effective management is able to guarantee equitable management of economic, social and natural resources [8]. When planning and implementing the activities of the university, the environmental aspect requires no less 
attention than others, because a rather significant part of the educational institution's activity is related to the field of ecology.

Advancing the principles of sustainable development requires the formation of a new ecological consciousness. The multilayering of relations and connections between man and nature results in a complex structure of ecological consciousness. The ecological consciousness reflects not only the rational-intellectual sides of these relations and connections, but also the sensual-emotional side. For many years, the term "ecological consciousness" has not been formulated unambiguously. Most researchers understand ecological consciousness as a multidimensional phenomenon that manifests itself in a tendency toward environmentally oriented behavior. Researchers included the following components in the structure of ecological consciousness: beliefs, values, personal attitudes, environmentally oriented behavior; environmental knowledge / awareness.

F. Mayer et al. call an environmentally oriented consciousness a complex that includes knowledge, values and attitudes towards the environment, together with emotional inclusion [9].

Empirical studies on ecological consciousness focus on finding the dependencies of manifestations, characteristics, types of ecological consciousness, primarily on the current values of an individual, formed worldview, as well as age, individual life experience, age, gender. In the scientific literature there are two areas in the study of ecological consciousness. Some researchers consider ecological consciousness as a multidimensional, complex construct, others as one-dimensional, reducing its understanding to one of the components. P. Schultz uses the concept of environmental consciousness to refer to psychological factors associated with the predisposition of individuals to demonstrate environmentally oriented patterns of behavior. This approach does not include various types of pro-ecological behavior, other factors or psychological constructs that are usually associated with it: beliefs, values, attitudes, knowledge and others. From an analytical point of view, an environmentally conscious individual with environmentally oriented behavior is one who involved in a wide range of types of environmentally oriented behavior, and also adheres to certain values and attitudes associated with this type of behavior [10, 11].

M. Sanchez suggested considering the affective, cognitive, dispositional, and active aspects of ecological behavior. He described ecological consciousness as a multidimensional phenomenon, that manifests itself in a tendency to participate in environmentally oriented activities [12].

P. White positions ecological consciousness as based on eco-centric human value orientation. Ecological consciousness guides the individual to the values of internal wealth and the laws of nature, the value of humanity as part of nature, which implies a manifestation of empathy. The transition to ecological awareness occurs when there is respect and recognition of the value of a man-made environment, the awareness of dependence on it, which causes concern and actions to preserve nature.

P. White, based on research, identified and described the following characteristics of ecological consciousness: 1) awareness of their involvement in the natural environment; 2) identify yourself with the natural environment; 3) evaluating oneself as part of nature; 4) deep feelings about the destruction of the natural environment; 5) desire for self-realization, focused on meaningful interaction with the natural environment; 6) the realization that global crises are the result of industrial development and consumption; 7) an unconscious need to connect with the natural environment, which is updated by the inevitability of negative consequences [13].

Considering the activities of builders and architects from the perspective of sustainable development, it is necessary to recognize that architects can have a significant impact on restoring ecological balance and ensuring a high quality of life for people, creating an architectural environment that meets human needs and at the same time preserves or even 
improves the state of nature. M. Pitt and co-authors believe that such an architectural environment can be considered sustainable. Because sustainable construction and architecture focus mainly on the technological characteristics of objects, their aesthetic expressiveness and style qualities become a certain problem [14]. The practical application of the principles of sustainable concept led to the creation in 2010 of the Council on Environmentally Sustainable Architecture on the basis of the Union of Architects of Russia, which is intended to consider the formation in the professional environment of architects of a new attitude to the protection of the environment for Russia, the creation and operation of buildings and structures, and the development of territories and settlements.

Along with the term "sustainable architecture", other concepts are often used in the literature: "green architecture", "green construction", "environmental architecture", "energy-efficient and smart construction", "high-tech architecture". All these concepts are related to different degrees to the special technology for the construction and operation of buildings, the purpose of which is to reduce the level of consumption of energy and material resources while maintaining or improving the quality of buildings and the comfort of their internal environment. Moreover, not all of the concepts indicate qualitative signs of architecture and the aesthetic design of buildings.

The purpose of this study was to study the formation of the elements of sustainable development - ecological consciousness and environmentally oriented activities of learners of the construction university. To do this, it is necessary to analyze the vision of the concept, the actions taken by learners of higher technical educational institutions and workers in the construction industry.

\section{Materials and Methods}

In this study, a semi-structured questionnaire was used, the survey involved masters of several directions for Bachelor's degree: architects, builders, urban planners, students of Moscow State University of Civil Engineering, a total of 53 people. Interviewed respondents with experience in the profession for at least two years, aged 22 to 29 years, many had experience in project teams.

Research questions were developed based on a literature review. Pilot testing was carried out to confirm the reliability of the questionnaire, some wording of the questions was clarified, which increased the likelihood that respondents would give a similar answer when re-examining. External and internal validity was provided through a literature review, as well as the views expressed by three experts in this field. All participants were explained in detail the meaning of the questionnaire, its importance. Respondents were guaranteed confidentiality, all of them voluntarily participated in the study. A post-questionnaire interview was conducted to clarify some responses.

After filling out the questionnaire, respondents filled out a structured questionnaire (28 points) to measure aspects of environmentally oriented behavior. It was created for this study based on the Environmental Action Scale (EAS) [15] and the Multidimensional scale of pro-environmental behavior [16].

The claims were rated on the Likert scale, 5 points, (from 0 "fully agree" to 4 "absolutely disagree").

\section{Results}

First, data on the questionnaire were received and processed. 
1. Are you aware of the concept of sustainable development? If so, from what sources did you hear about it? Evaluate how important it is for construction workers to know about this concept (from 1 to 5 points).

The data obtained showed that about half of the respondents were familiar with the Concept (47\%), and urban planners showed the greatest awareness $(75 \%)$. However, none of the respondents $(100 \%)$ indicated that he (she) has a full (deep) understanding of the Concept. Most of the respondents $(60 \%)$ said that they received knowledge about the Concept of sustainable development in the process of studying at the university, $26 \%-$ from books and scientific papers, $11 \%$ said that they learned about the Concept from specialized seminars and training programs. The average score for respondents assessing the importance of knowledge of the Concept was 3.8 (with a maximum of 5).

2. What do you think is most important in a project based on sustainable development: construction costs, environmental issues, labor productivity of workers or appearance (aesthetic side)?

The findings showed that $45 \%$ of builders $(n=21)$ said that the environment was the most important factor to consider when designing a project, $25 \%$ said that labor productivity was the most important factor, and $29 \%$ said that the cost of construction was the most important.

In the sample, $53 \%$ indicated that environmental protection was the most important, $28 \%$ indicated cost, $12 \%$ indicated productivity, $6 \%$ indicated aesthetics was the most important factor in the project based on sustainable development.

3. Are you aware of the concept of green construction / architecture? If so, from what sources did you find out about it? Evaluate how important it is for construction workers to know about the concept of green construction / architecture (from 1 to 5 points).

The data obtained showed that regardless of the direction for Bachelor's degree, the majority of respondents were familiar with the Concept $(81 \%)$. However, the vast majority $(87 \%)$ noted that their ideas about green construction / architecture are scattered (fragmentary).

The majority of respondents (68\%) said that they gained knowledge of the Concept by reading papers and literature on the profession. Only $21 \%$ learned about it from training seminars. 9\% replied that they learned about the green building concept from work colleagues or a supervisor. The average score of respondents' assessment of the importance of knowledge about green construction / architecture, regardless of the direction of preparation, was 2.7 (maximum 5).

4. What are the main challenges for architects and builders in the design and construction of an ecological building?

Most of the respondents believed that the main problem that they will face in the design and construction of ecological buildings is the lack of awareness among customers (clients) about environmental construction / architecture (47\%). Then, the materials used $(21 \%$ of respondents), energy saving (19\%) and the choice of construction site (13\%) are delivered.

5 . What are the main problems in the construction (design) of green buildings related to your work (profession)?

The surveyed builders $(n=21)$ identified the following main problems: a place for construction and energy saving (28\% respondents per each). Lack of customer awareness of the problems of construction (design) of green buildings was considered the main problem that they would face in the construction of green buildings, $19 \%$ of builders. The construction materials used were cited as the main problem by $22 \%$. Urban planners $(\mathrm{n}=$ 16) rated the construction site as the main problem (50\% of votes). Energy saving and lack of customer awareness were rated as major problems by $19 \%$ and $26 \%$ respectively. Architects $(n=16)$ highlighted lack of customer awareness as the main problem $(47 \%$ of 
respondents). Energy efficiency and materials used were rated as the main problems by $16 \%$ and $31 \%$ respectively.

6. Do you think government bodies are sufficiently supportive of green construction / green architecture practice?

The data obtained indicate that all respondents (100\%) believed that government incentives given to builders and architects to practice and promote green construction were insufficient.

7. Are you ready to personally participate in the creation or promotion of green construction/ architecture projects?

According to the results of the survey, $90 \%$ of respondents were ready to develop or promote green construction / architecture projects. At the same time, all surveyed urban planners (100\%) expressed such readiness. However, none of the respondents had experience in implementing relevant projects.

The results of measuring aspects of environmentally oriented behavior are given below (Table 1).

Table 1. Environmentally oriented behavior statistics.

\begin{tabular}{|c|c|c|c|}
\hline & $\mathrm{M}$ & $\sigma$ & $\alpha$ \\
\hline Economy (thrift) & 2.41 & 0.673 & 0.68 \\
\hline Altruism & 1.77 & 0.597 & 0.82 \\
\hline Justice & 3.23 & 0.598 & 0.81 \\
\hline Emotional attitude & 2.54 & 0.516 & 0.74 \\
\hline Environmentally friendly actions & 1.85 & 0.402 & 0.72 \\
\hline
\end{tabular}

Note. $\mathrm{M}$ is the average value in the sample, $\sigma$ is the standard deviation, $\alpha$ is the Cronbach coefficient for $\mathrm{p}=0.01$.

Economy (thrift) - actions against consumer attitudes towards nature, reckless waste of natural resources, and they can affect sustainable development. This mode of behavior forms a way of life characterized by reduction of consumption of natural resources, reduction of human impact on nature. The obtained average value $\mathrm{M}=2.41$.

Altruism implies a predisposition to satisfy the interests of others with little or no interest in one's own benefit. Also implies the presence of motivation to maximize the wellbeing of other people, future generations. The average value $\mathrm{M}=1.77$.

Justice means treating others fairly, avoiding bias and discrimination in the distribution of goods. This indicator also assumes fair consumption and distribution of natural resources and empowerment of people, in order to minimize existing disparities in natural resource income, educational opportunities and access to services. The obtained average value of $\mathrm{M}$ $=3.23$.

The emotional attitude is manifested in meeting the need for contact with fauna, flora, and natural environment. This indicator involves pleasant emotions, such as: joy, calmness, complacency and positive mood from exposure with an environment containing natural characteristics, or an almost natural environment. The obtained sample average value $\mathrm{M}=$ 2.54 .

Ecologically oriented actions are manifested in the following aspects of behavior: willingness to act for the good of nature and the environment in an ecological way, willingness to contribute to the preservation of the environment, which helps to achieve the purposes of sustainable development. The average sample value $M=1.85$. This indicator is most important for assessing environmentally oriented professional activities. 


\section{Discussion}

The results of the questionnaire and qualitative analysis of the results revealed the awareness of students about the problems of construction (design) of green buildings. No one claimed to have a "deep understanding" of the goals and objectives of sustainable development, although many were familiar with this concept, especially urban planners. Lack of awareness of customers (clients) of design and construction of green buildings is an obstacle for development of this area. Most of the respondents expressed willingness to promote green construction / architecture, however, none of the respondents took appropriate practical steps.

Survey participants expressed confidence that the future in the design and construction of green buildings is more promising. Natural resources are rapidly being depleted and environmental protection is becoming an urgent necessity. It was evident that the necessary administrative measures were not sufficiently taken to recognize, support and promote green building and architecture. The results indicate the need for such measures.

Regarding the aspects of environmentally oriented behavior, the average of "altruism" $\mathrm{M}=1.77$ says that this indicator was the least expressed in comparison with other aspects of environmentally oriented behavior. The obtained average of "fairness" $M=3.23$ is the largest compared to others, which reflects the expressed request for fair consumption and distribution of natural resources. The obtained average value of "economy (thrift)" $\mathrm{M}=$ 2.41 indicates an expressed desire for rational consumption of natural resources. The average value of "emotional attitude" $\mathrm{M}=2.54$ testifies to the expressed emotional component of environmentally oriented behavior in respondents.

The obtained average value of $\mathrm{M}=1.85$ for the indicator "environmentally friendly actions" does not indicate a clearly expressed desire of respondents to take practical steps to preserve the environment, which may be due to the indirect influence of many factors: unwillingness to change the usual ways of work and interaction, inert thinking, environmental problems confusion, fatalism, fear [17]. In order to change this situation, a set of measures of an economic, social and educational nature is required.

\section{Conclusions and recommendations}

This study made it possible to better understand the problems of ecological consciousness and environmentally oriented behavior of learners at the construction university.

The introduction of economic incentives to increase the number of builders and architects practicing green construction and architecture, seminars and workshops for customers can accelerate environmental construction and architecture. Public authorities can develop special programs and provide tax incentives for customers who build green buildings, construction companies that carry out design and construction. The media should inform the public about environmental problems and hazards due to the rapid depletion of natural resources and pollution of environmental components.

The topics discussed above raise questions that scientists will face in building more sustainable societies. These issues could give impetus to further discussion: 1 . It is necessary to clarify the main provisions of concept of "sustainable development" for certain sectors of the economy. Is it possible for economic growth to continue and for society to remain on the path of sustainable development? 2. What can scientists do, apart from writing scientific papers, to help people adopt environmentally responsible behavior?

It is necessary to assess the impact of higher education on the formation of sustainable development and environmentally oriented behavior of learners. M. Barth believes that it is necessary to regularly develop competencies for sustainable development in order to implement some approaches of sustainable development in higher education institutions. 
The level of ecological consciousness and behavior achieved by learners is often not the result of education according to the sustainable development in universities. Each action or institutional policy for the implementation of sustainable development should correspond to their goals and indicators to be evaluated [18].

Future studies should be carried out to explain the reasons for the low effectiveness of measures aimed at the formation of environmentally friendly activities of university students to achieve the goals of sustainable development. Architects and builders need to be encouraged to promote environmentally responsible professional solutions to protect the health and well-being of the population and the beneficial state of the ecosystem.

\section{References}

1. T. Salimova, N. Guskova, E. Neretina,. Int. J. of Inn. and Sust. Develop., 9 (3/4), 246261 (2015)

2. Report of the World Commission on Environment and Development: Our Common Future. https://sustainabledevelopment.un.org/content/documents/5987our-commonfuture.pdf

3. W. Adlong, Int. J. of Sust. in High. Ed., 14 (1), 56-70 (2013)

4. Ch., Gore, J. of Int. Develop., 27 (6), 717-732 (2015)

5. Proposal for a global action programme on education for sustainable development as follow-up to the united nations decade of education for sustainable development (DESD) after $2014 /$ UNESCO. Gen. Conf., 37 ${ }^{\text {th }}$ Sess. Paris (2013) https://unesdoc.unesco.org/ark:/48223/pf0000224368

6. R. Kankovskaya, Proc. CIRP 48, $449 \quad-\quad 453 \quad$ (2016) https://core.ac.uk/download/pdf/82731034.pdf

7. J. Crotty, S.M. Hall, Sust. Develop., 22 (5), 311-320 (2014)

8. M.E. Kraft, S.R. Furlong, Public Policy: Politics, Analysis, and Alternatives (California, CQ Press, 2018)

9. F.S. Mayer, C.M. Frantz, E. Bruehlman-Senecal, K. Dolliver,. Behav. 41, 607-643, (2009)

10. P.W. Schultz, A.M. Tabanico, J. of Appl. Soc. Psych., 37(6), 1219-1247 (2007)

11. M-L. Felonneau, M. Becker, Rev. Int. de Psych. Soc., 4(21), 25-53 (2008)

12. M.J. Sánchez, R. Lafuente, Rev. Int. de Soc. 68, 731-755 (2010)

13. P.R. White, Ecopsych., 3(1), 41-50 (2011)

14. M. Pitt, M. Tucker, M. Riley, J. Longden, Int. J. of Const. \& Arch. Inn 9, 201-224 (2009)

15. S. Alisat, M. Riemer, J. of Env. Psych., 43, 13-23 (2015)

16. L.R. Larson, R.C. Stedman, C.B. Cooper, D.J. Decker,. J. of Env. Psych. 43, 112-124 (2015)

17. E. Manolas,. Aeg. J. of Env. Scie. 1, 13-21 (2015)

18. M. Barth, Implementing Sustainability in Higher Education: Learning in an age of transformation (N-Y., Routledge, 2014) 